\title{
Health Indicators of Students in Weekly Dynamics in Conditions of Distance Learning and Self-Isolation During the Period of COVID-19
}

\author{
Bashkireva T. ${ }^{1}$ Bashkireva A. ${ }^{1, *}$ Ermakova N. ${ }^{2}$
}

\author{
Morozov A. ${ }^{3}$ Yulina G. ${ }^{4}$ \\ ${ }^{1}$ Ryazan State University named after S.A. Yesenin, 390000, Ryazan, Russia \\ ${ }^{2}$ Peoples' Friendship University of Russia, 117198, Moscow, Russia \\ ${ }^{3}$ Research Center, The Federal State Institution "Research Institute of the of the Federal penitentiary service of Russia", \\ 125130, Moscow, Russia \\ ${ }^{4}$ Moscow State University of Technology and Management named after K.G. Razumosky, 109004, Moscow, Russia \\ *Corresponding author. Email: bashkirevat@bk.ru
}

\begin{abstract}
The article presents the results of a study of students' health in terms of cardiovascular system indicators in conditions of distance learning and self-isolation during the period of COVID-19. The analysis of circusseptal (near-weekly) rhythms in students revealed the dominance of synchronization of indicators of the cardiovascular system in conditions of distance learning. It indicates that the students chose the same mode of educational activity, living independently of each other at a considerable distance, and it turned out to be safe for the cardio-respiratory system of students. The data obtained make it possible to recommend a combination of traditional and distance learning modes using modern IT technologies, subject to the development of sanitary and hygienic standards that are safe for health.
\end{abstract}

Keywords: health, weekly (circaseptan) rhythms, cardiovascular system, self-isolation, COVID-19

\section{INTRODUCTION}

At the end of 2019, the world community faced the problem of choosing a farther path in all directions. In March 2020, the World Health Organization announced the beginning of the COVID-19 pandemic, which made its adjustments to the global educational space and was called the "Era of the COVID-19 pandemic" [13]. In March 2020, Russia transferred educational organizations to distance learning and announced self-isolation. In the education environment, we faced the problem of how to teach remotely using information and communication technologies [8-9]. Since the time of students' work at the computer will increase, the likelihood of physical inactivity will evident [4]. How will the body of students cope with an intense load in conditions of physical inactivity?

In our work, we focus on the parameter of cardiovascular indicators state of health of students in terms of distance learning [11].

Research by scientists established (N.A. Perna (1925), A.L. Chizhevsky (1930), DH Myers, P. Davies (1978), V.P. Yaryshkin (1993), V.N. Druzhinina (1995), EL Rossi (1991)) that not only biological, physiological processes, but also the dynamics of mental activity, including emotional states, are subject to regular fluctuations [14].
The biorhythmological organization of physiological functions can represent as a set of functionally and spatially distinguished oscillators, the frequencies of which are the natural frequencies of functioning physiological systems (Chibisov S.M., Frolov V.A., Agadzhanyan N.A., Halberg F. et al., 2006) [7]. During the period of adaptation, the spectrum of physiological rhythms interchanged. Their harmonic agreement achieved due to the desire for synchronization (Agadzhanyan N.A. in SAVT., 1999, 2007) [5]. The circulatory system considered a universal indicator of the adaptive activity of the whole organism.

Any biological phenomenon, any physiological reaction is periodic functional systems of the body are rhythmic.

Biological rhythms identified at all levels of life organization and evolutionary form of adaptation that determines the survival of living organisms. Rhythm in biological living systems of systems is a necessary condition for existence. For the cardiovascular system, a temporary measure of the cardiac cycle, consisting of strictly related phases [6]. However, it noted that the heart rate influenced by such factors as disease, age, features of professional activity, fitness, low/high level of physical activity. Everyone knows that low levels of physical activity can negatively affect health. It due to the formation of oxygen deficiency in cells and accompanied by hypoxia and hypodynamia. 
In connection with the intensive spread of the COVID-19 pandemic, university students transferred to distance learning mode $[1 ; 3 ; 10]$. It determined the goal of our work: to study the health indicators of students in weekly dynamics in the conditions of distance learning and selfisolation during the period of COVID-19 [2; 12].

\section{METHOD}

The cardiovascular system is the most sensitive to any influences of environmental factors as an indicator of body health. The Belgian test "Reaction of the cardiovascular system to load in the form of torso bends" chosen for the study. This technique select's because it is easy to perform; minimal time expenditures provides physical activity on all the muscles of the trunk, especially if a person is limited in active movements for a long time for any reason.

The students themselves recorded the indicators for three weeks during the daily maximum: $12.00,16.00$ hours and the daily minimum - 8.00 and 21.00 hours. The results were processed mathematically $(\mathrm{M} \pm \mathrm{m} ; \pm \delta)$ and statistically $(\rho ; F)$ in Excel software; Statistica. The indicators of biological rhythms also calculated: mesor, amplitude, acrophase, bathiphase using the statistical program Cosinor.

Comparison of health indicators carried out in weekly dynamics (circaseptan rhythm).

The study involved 43 students in various fields of study. Sex characteristics not included in the analysis.

\section{RESULTS AND DISCUSSION}

The analysis of the data obtained made it possible to identify the group health norm $(0.78 \pm 0.11)$, which under the method corresponds to the average level (0.61-0.9). The group health norm throughout the study observed in $22.9 \%$ of students, below norm values (good health) - in $39.6 \%$, above the norm values (undesirable health) - in $37.5 \%$. The risk group with indicators of poor health was $12.5 \%$. This group had prerequisites for desynchronosis. The results of the correlation analysis showed reliable biorhythmological differences in the circaseptan (nearweekly) rhythm in the health status of students (tab. 1).

Table 1 Correlations of circus-septal rhythms by indicators of the cardiovascular system students in distance learning conditions during the COVI-19 period

\begin{tabular}{|c|c|c|c|c|c|c|c|}
\hline \multirow[b]{2}{*}{ 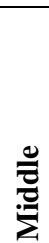 } & \multicolumn{7}{|c|}{ Days of the week } \\
\hline & 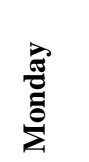 & 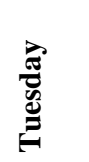 & 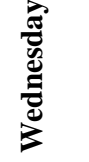 & 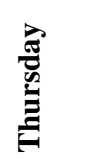 & $\stackrel{\Xi}{E}$ & 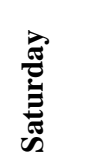 & 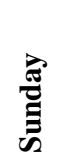 \\
\hline$\rho$ & 0,24 & 0,52 & 0,65 & 0,74 & 0,75 & 0,51 & 0,69 \\
\hline $\mathrm{P}$ & $>0,05$ & $<0,05$ & $<0,01$ & $<0,001$ & $<0,001$ & $<0,05$ & 0,01 \\
\hline
\end{tabular}

The table shows that the level of health in terms of the cardiovascular system significantly decreases by Thursday, reaching a maximum on Friday and slightly increasing by Sunday. The time the group worked at the computer on the indicated days was 4.5 hours. Whereas on Wednesday, the load in conditions of information and communication technologies was 7.4 hours.

Figure 1 shows the indicators of the cardiovascular system students in weekly dynamics (in the conditions of distance learning and self-isolation caused by the COVID-19 pandemic).

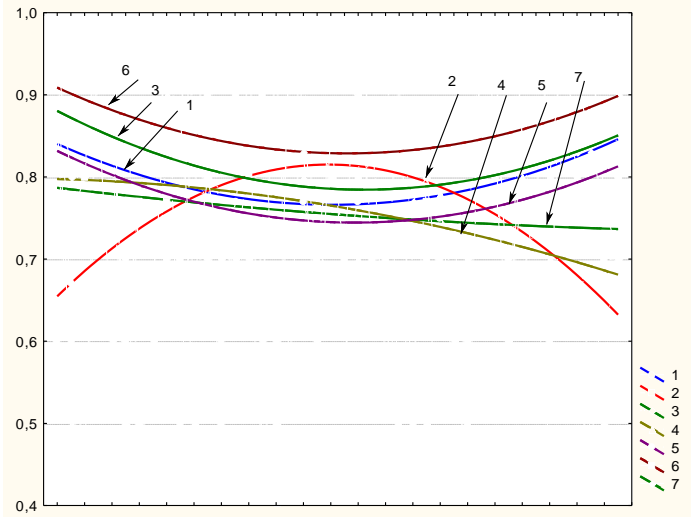

Figure 1 Indicators of the cardiovascular system students in the weekly dynamics (in conditions of distance learning and self-isolation caused by the COVID-19 pandemic)

Synchronization of indicators of the cardiovascular system observed on Monday, Wednesday, Friday and Saturday. Analysis of educational activities showed that these days 
there were a significant number of tasks that they performed in the morning and evening. Environment metrics are asynchronous throughout the study period. It was between 9.30 and 13.30 hours that the students were busy in classes with intensive use of Internet resources. Figure 2 shows the individual student profile of circaseptan (peri-weekly) rhythms in terms of cardiovascular indicators (in conditions of distance learning and self-isolation caused by the COVID-19 pandemic). The amplitude of the student cardiovascular system was $0.51 \pm 0.4$, which corresponds to insignificant individual variations of this indicator.

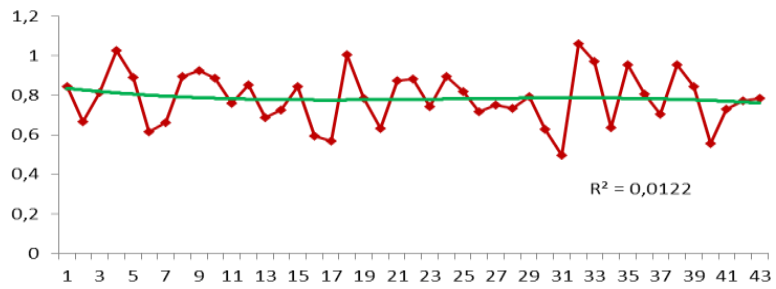

Figure 2 Individual profile of student circaseptan rhythms by indicators cardiovascular system in the approximation of the third-degree polynomial (in conditions of distance learning and self-isolation caused by the COVID-19 pandemic)

Acrophase characterizes the maximum values of the variable, in this case, physiological indicators, calculated through a one-component sinusoidal approximation and amounted to $0.28 \pm 0.06$ according to the index of the cardiovascular system of students. Batiphase represents the minimum values of a one-component sinusoidal approximation and has minor differences among students $0.23 \pm 0.05$. The data obtained indicate that group synchronization in distance learning mode dominates in the group of surveyed students. We did not notice this phenomenon in our studies of the usual regime.

\section{CONCLUSION}

The study of circaseptan (near-weekly) rhythms in students revealed the dominance of synchronization of the cardiovascular system indicators in the context of distance learning. It indicates that students chose the same mode of educational activities, independently of each other, living at a considerable distance. Therefore, variations in individual indicators of the cardiovascular system did not differ significantly. We did not observe such a phenomenon in traditional training conditions, but noted in cases of joint activities and living with rotational teams. The data obtained indicate that the distance-learning mode chosen by the students turned out to be safe for the cardirespiratory system. However, it noted that the influence of technical means on the visual analyzer for intensive training in remote conditions not studied. Thus, the data obtained make it possible to recommend the combined use of traditional and distance learning modes, subject to the development of sanitary and hygienic standards that determine a safe time for working at a computer.

\section{REFERENCES}

[1] P. Ayres, J. Sweller (2014) The split-attention principle in multimedia learning. In R. E. Mayer (Ed.), The cambridge handbook of multimedia learning (2nd ed.,). Cambridge University Press, 206226. DOI: https://doi.org/10.1017/ CBO9781139547369.011

[2] W. Bao (2020) COVID-19 and online teaching in higher education: A case study of Peking University. Human Behaviour and Emerging Technologies, 2 113115. DOI: https://doi.org/10.1002/hbe2.191

[3] B. Levent (2012) Use of online video cases in teacher training. Social and Behavioral Sciences. 47 10071011. DOI: https://doi: 10.1016/j.sbspro.2012.06.770

[4] G. Blomberg, K. Stürmer, T. Seidel (2011) How pre-service teachers observe teaching on video effects of viewers' teaching subjects and the subject of the video. Teaching and Teacher Education 27711311140. DOI: http://dx.doi.org/ 10.1016/j.tate.2011.04.008

[5] S. Chibisov, G. Cornélissen, F. Halberg (2007) Longitudinal monitoring of blood pressure and heart rate, In: Proceedings, International Symposium, Problems of ecological and physiological adaptation, People's Friendship University of Russia, Moscow 510514.

[6] B. Collins, H.S. Kaplan, M. Cavey, K.R. Lelito, A.H. Bahle, Z. Zhu, A.M. Macara, G. Roman, O.T. Shafer, J. Blau (2014) Differentially timed extracellular signals synchronize pacemaker neuron clocks, PLoS Biol, 121001959.

[7] G. Cornelissen, F. Halberg, R.B. Sothern, D.C. Hillman, J. Siegelova (2010) Blood Pressure, heart rate and melatonin cycles synchronization with the season, earth magnetism and solar flares, J. Scripta medica, 83 1.

[8] Kinga Lachowicz Tabaczek, Beata Bajcar 2018 Thinking further ahead: Can temporal distance in thinking about one's future influence affect experienced by people with low self-esteem? Personality and Individual Differences 131 197205. DOI: https://doi.org/10.1016/j.paid.2018.04.039

[9] D. Lederman (March 18, 2020). Will shift to remote teaching be boon or bane for inline learning? Inside Higher Ed. Retrieved, Electronic resource.

[10] Petsakou Afroditi, Sapsis P. Themistoklis, Blau Justin. 2015 Circadian Rhythms in Rho1 Activity 
Regulate Neuronal Plasticity and Network Hierarchy Cell, 162, 823835. DOI:

http://dx.doi.org/10.1016/j.cell.2015.07.010

[11] Seidel Tina, Blomberg Geraldine, Renkl Alexander (2013) Instructional strategies for using video in teacher education. Teaching and Teacher Education 34, 665.

[12] Schnotz W., Bannert, M. (2003) Construction and interference in learning from multiple representation. Learning and Instruction 13 141156. DOI: https://doi.org/10.1016/S0959-4752(02)00017-8.

[13] UNESCO IESALC (2020). COVID-19 and higher education: Today and tomorrow. Impact analysis, policy responses and recommendations, Electronic resource.

[14] Zhang, W., Wang, Y., Yang, L., Wang, C. (2020). Suspending classes without stopping learning: China"s education emergency management policy in the COVID-19 outbreak. Journal of Risk and Financial Management. 1355 26. DOI:

https://doi.org/10.3390/jrfm13030055 